\title{
Superior caval venous syndrome after atrial switch procedure: relief of complete venous obstruction by gradual angioplasty and placement of stents
}

\author{
Ina Michel-Behnke, Karl-Jürgen Hagel, Jürgen Bauer, Dietmar Schranz \\ Department of Paediatric Cardiology, Justus-Liebig University, Gießen, Germany
}

\begin{abstract}
Superior caval venous syndrome is one of the late problems known to occur after Mustard repair of complete transposition. Reoperation may leave residual stenosis, and carries substantial risk for the patient. It is now feasible to use intravascular stents to overcome systemic venous baffle obstructions, and such an approach is probably more effective. The purpose of our study therefore, was to assess immediate and medium term results of inserting stents subsequent to gradual balloon enlargement of acquired atresia of the intraatrial baffle in patients who had undergone an atrial switch operation. We investigated five patients with complete obstruction of the superior caval venous pathway at perforation of the atretic segment was achieved using a guide wire technique. The procedure was successful in all patients. Gradual angioplasty was performed and intravascular stents were implanted. The pressure in the superior caval vein dropped to normal values, symptoms improved, and the patency of the newly created venoatrial communication was proven at mid-term follow-up. Thus critical obstructions at the superior caval venous pathway after the Mustard procedure can be reopened by interventional catheterization. Implantation of balloonexpandable intravascular stents is safe and effective in the acute relief of the obstructions, but careful longterm follow-up is mandatory.
\end{abstract}

Key words: Mustard procedure; baffle obstruction; balloon angioplasty; stents.

$\mathrm{T}$ HE LONG-TERM RESULTS OF THE MUSTARD OR Senning procedures are influenced by dysfunction of the systemic right ventricle, tricuspid regurgitation, arrhythmia, and systemic or pulmonary venous obstruction. ${ }^{1,2}$ While reduced contractility and arrhythmia may lead to congestive heart failure, elevated pressure in the superior caval vein can cause a variety of symptoms, summarized as the superior caval venous syndrome. ${ }^{3}$

Previously, superior caval venous obstruction occurring after atrial switch operation necessitated

Correspondence to: Dr.Ina Michel-Behnke, Department of Paediatric Cardiology Justus-Liebig University, Feulgenstraße 12, 35385 Gießen, Germany. Tel: 049641-99 43460; Fax: 049-641-99 43469

Accepted for publication 19 March 1998 surgical revision of the baffle, with substantial risk for the patient, and did not eliminate the potential for recurrence. 3,4

Recently, there have been several case reports describing percutaneous balloon angioplasty as an important alternative for treatment of severe stenosis leading to the superior caval venous syndrome. ${ }^{5-7}$ Management of occlusion at the level of the baffle, with no visible communication to the systemic venous atrium, has rarely been attempted by transcatheter techniques. ${ }^{5,6,8}$ We report a series of 5 patients in whom we were able successfully to perforate an atretic venoatrial connection. Sequential balloon angioplasty then permitted gradual enlargement of the newly created channel, and subsequent placement of stents established a persistently wide venoatrial communication. 


\section{Materials and methods}

\section{Patients}

From April 1995 to December 1996, we encountered five patients with complete transposition suffering the superior caval venous syndrome 5 to 16 years after an atrial switch operation using the Mustard procedure (Table 1). All had a distended segment of the superior caval vein with collateral pathways via the azygos vein. In one patient with complete obstruction of the superior caval vein as well as the iliac veins, the umbilical vein was recanalised. In all patients, we attempted to reopen the atretic venoatrial junction using interventional techniques and implantation of stents.

\section{Cardiac catheterisation}

Parental (and where applicable, patient) informed consent was obtained according to institutional review board protocol. The percutaneous procedures were performed under general sedation with ketamine and diazepam or midazolam. In four patients, we used a standard percutaneous femoral approach. In all, it was necessary to enter the superior caval vein via the left or right subclavian vein. Hemodynamic measurements were obtained during complete rest (Table 2). Simultaneous angiography into the superior caval vein and the systemic venous atrium, respectively, revealed the extent of the venoatrial obstruction, the width of the superior caval vein, and the distance to the mitral valve (Table 2). In one patient with occluded iliac veins, angiographic visualisation was possible only from the superior caval vein. A $4 \mathrm{~F}$ multipurpose catheter was advanced into the superior caval vein and, with the tip firmly against the obstruction, the soft or stiff end of a guide wire (0.018-0,035 in) was used to recanalise the venoatrial junction. Once the obstruction was passed with the wire, the multipurpose catheter was advanced. In three patients, the tight obstruction was dilated with coronary angioplasty catheters. Sequential angioplasty was then performed with a $6 \mathrm{~mm}, 8 \mathrm{~mm}$ and/or $10 \mathrm{~mm}$ balloon for so as gradually to augment the venoatrial junction. To abolish restenosis, Palmaz-Schatz stents of different sizes $(18 \mathrm{~mm}$ long, $3.4 \mathrm{~mm}$

Table 1. Clinical characteristics of 5 patients

\begin{tabular}{lllllll}
\hline $\begin{array}{l}\text { Pat. } \\
\text { No }\end{array}$ & $\begin{array}{l}\text { age } \\
(\mathrm{yy})\end{array}$ & $\begin{array}{l}\text { height } \\
(\mathbf{c m})\end{array}$ & $\begin{array}{l}\text { weight } \\
(\mathbf{k g})\end{array}$ & sex & method and age at previous surgery & site of venous obstruction \\
\hline 1 & 16 & 166 & 69 & $\mathrm{~m}$ & $\begin{array}{l}\text { Mustard procedure, 18 months } \\
\text { Mustard procedure, 22 months }\end{array}$ & $\begin{array}{l}\text { SCV, complete } \\
\text { SCV, complete } \\
\text { Iliac veins, incomplete }\end{array}$ \\
3 & 18 & 183 & 71 & $\mathrm{~m}$ & SCV, complete \\
4 & 10 & 150 & 32 & $\mathrm{~m}$ & $\begin{array}{l}\text { Mustard procedure, 10 months } \\
\text { Mustard procedure, 24 months } \\
\text { VSD-patch, Banding, 10 months } \\
\text { De-banding, Mustard procedure,30 months }\end{array}$ & SCV, complete \\
\hline
\end{tabular}

Abbreviations: $\mathrm{m}=$ male, $\mathrm{SCV}=$ superior caval vein, $\mathrm{VSD}=$ ventricular septal defect, $y y=$ years, $\mathrm{cm}=$ centimetres, $\mathrm{kg}=\mathrm{kilograms}$

Table 2. Hemodynamic measurements before reopening of venoatrial obstruction and interventional procedure data

\begin{tabular}{|c|c|c|c|c|c|c|c|}
\hline $\begin{array}{l}\text { Pat. } \\
\text { No }\end{array}$ & $\begin{array}{l}\mathrm{SCV} \\
\text { pressure } \\
\text { mmHg }\end{array}$ & $\begin{array}{l}\text { RAP } \\
\text { mmHg }\end{array}$ & $\begin{array}{l}\text { distance of } \\
\text { obstruction } \\
\text { mm }\end{array}$ & $\begin{array}{l}\text { venous access for } \\
\text { recanalisation/ } \\
\text { stent placement }\end{array}$ & $\begin{array}{l}\text { reopening } \\
\text { procedure }\end{array}$ & type of stent & $\begin{array}{l}\text { final } \\
\text { stent diameter } \\
\mathrm{mm}\end{array}$ \\
\hline 1 & 15 & 7 & 10 & $\begin{array}{l}\text { Left subclavian vein } \\
\text { Right subclavian vein }\end{array}$ & $\begin{array}{l}0.035^{\prime} \text { guide wire } \\
\text { soft tip }\end{array}$ & $\begin{array}{l}\text { Palmaz-Schatz } \\
30 \mathrm{~mm}, \varnothing 12-18 \mathrm{~mm}\end{array}$ & $\begin{array}{l}12 \\
\text { redilated: } 15\end{array}$ \\
\hline 2 & 16 & $5 *$ & 12 & Left subclavian vein & $\begin{array}{l}0.025^{\prime \prime} \text { guide wire } \\
\text { stiff tip }\end{array}$ & $\begin{array}{l}\text { Palmaz-Schatz } \\
30 \mathrm{~mm}, \emptyset 12-18 \mathrm{~mm}\end{array}$ & $\begin{array}{l}12 \\
\text { redilated: } 18\end{array}$ \\
\hline 3 & 16 & 8 & 15 & $\begin{array}{l}\text { Right cubital vein } \\
\text { Left femoral vein } \\
\text { Right jugular vein }\end{array}$ & $\begin{array}{l}0.035 " \text { guide wire } \\
\text { stiff tip }\end{array}$ & $\begin{array}{l}\text { Palmaz-Schatz } \\
18 \mathrm{~mm}, \varnothing 7-9 \mathrm{~mm} \\
2 \mathrm{x}\end{array}$ & $\begin{array}{l}8 \\
8\end{array}$ \\
\hline 4 & 17 & 9 & 16 & $\begin{array}{l}\text { Right subclavian vein } \\
\text { Right femoral vein }\end{array}$ & $\begin{array}{l}0.018^{\prime \prime} \text { guide wire } \\
\text { stiff tip }\end{array}$ & $\begin{array}{l}\text { Palmaz-Schatz } \\
40 \mathrm{~mm}, \varnothing 12-18 \mathrm{~mm}\end{array}$ & $\begin{array}{l}14 \\
\text { redilated: } 16\end{array}$ \\
\hline 5 & 18 & 7 & 20 & Right subclavian vein & $\begin{array}{l}0.018 \text { "guide wire } \\
\text { stiff tip }\end{array}$ & $\begin{array}{l}\text { Palmaz-Schatz } \\
30 \mathrm{~mm}, \emptyset 12-18 \mathrm{~mm}\end{array}$ & 12 \\
\hline
\end{tabular}

All pressure measurements are mean values.* $=$ RAP after recanalisation before stent placement

Abbreviations: $\mathrm{SCV}=$ superior caval vein, $\mathrm{RAP}=$ right atrial pressure. 
O.D.;P188M, $30 \mathrm{~mm}$ long, 3.4mm O.D.; P308M or $40 \mathrm{~mm}$ long, $3.4 \mathrm{~mm}$ O.D.; P4014, Johnson and Johnson Interventional Systems) were delivered from the subclavian or femoral approach through a long sheath. The recommended size of the stent was defined by the extent of the obstructed lesion and the width of the adjacent superior caval vein. Sizing was chosen to abolish any residual pressure gradient. The diameter was further influenced by age, height and weight of the patient, taking account of the need to increase the diameter by redilation as the patient grows. The sequence of interventional events for patient 4 is depicted in Figure 1.

Residual obstruction was excluded by postimplantation angiography and measurement of pressures. In all patients, prophylaxis against endocarditis was achieved with cefuroxime (25 $\mathrm{mg} / \mathrm{kg}$ ). All patients were heparinized during the procedure. Afterwards, the first two patients received warfarin for 6 weeks and 3 months to maintain an International Normalised Ratio of 3.5. For the subsequent patients acetylsalicylic acid ( 2 $\mathrm{mg} / \mathrm{kg} /$ day) was given for 12 months.

\section{Follow up catheterisation}

Restudy was undertaken 6 weeks to 3 months after implantation of the stents. In 3 patients redilation was planned prospectively. In patients 3 and 5, residual obstructions were seen following implantation of a (P188M) and (P308M) stent, respectively. Additional stents were deployed during a second procedure, therefore, when the first stent was expected to be well endothelialised, thus reducing the risk of dislocation. The additional stents (P188M) and (P308M) were placed in series, each overlapping by at least several millimetres until the obstruction was completely traversed by stents. Meanwhile 3 patients in clinically good condition, with no recurrence of symptoms of obstructed drainage of the superior caval vein, were checked for patency of the stent 1.5 years after the initial procedure to assess midterm results.

\section{Results}

The patients were between 8 and 18 years of age. Precise delineation of the site of obstruction was achieved in four patients by simultaneous angiography performed the superior caval vein and the systemic right atrium, with catheters in facing position. Perforation of the fibrotic obstructed segment was successfully achieved in all patients using guide wires. Subsequent gradual angioplasty failed to relieve the tightly obstructed segments, necessi- tating the use of balloon-expandable stents. Complete expansion of the stent produced a final diameter of the stenosed segment between 8 and $14 \mathrm{~mm}$. Rupture of the balloon occurred in 2 patients: insertion of another catheter permitted abolishment of the residual waist completely with no sequels.

There were no further complications. In patients 3 and 5 , the obstructed area could not be covered by a single stent, so a second stent was placed telescopically into the first after an interval of 6 weeks to 3 months without any problems.

In all, seven stents were placed in five obstructed segments, with a reduction of median pressure gradient from $10 \mathrm{mmHg}$ (range, 8 to $11 \mathrm{mmHg}$ ) to 3 $\mathrm{mmHg}$ (range, 1 to $4 \mathrm{mmHg}$ ) (Fig. 2).

Redilation to $15-18 \mathrm{~mm}$ was performed in 3 patients 6 weeks to 3 months after primary deployment of the stents. In short term follow up, angiography showed no intimal proliferation and no significant residual venoatrial pressure gradient could be detected. Three patients were investigated eighteen months after the interventional procedure. The stents remained patent, with a 2 and $3 \mathrm{mmHg}$ gradient, but with no evidence of fracture or compression. None required further redilation.

\section{Discussion}

Intravascular stents have gained increasing acceptance in the treatment of vascular obstructions. ${ }^{9-11}$ Little has been published on use of balloon-expandable intravascular stents for the relief of systemic venous obstructions in children, particularly for obstructions in the venous pathway after either the Senning or Mustard procedures. ${ }^{5-8}$ To our knowledge, there are only a few previous case reports, ${ }^{5-7}$ demonstrating that interventional techniques are feasible for opening atretic segments with no visible communication to the systemic venous atrium. We present here our current experience in the management of such obstructions.

Obstructions at the level of the baffle, hindering the systemic venous inflow to the left ventricle, as well as obstructions of the pulmonary venous pathway, are well known complications in the long term follow up of these patients., ${ }^{3,4,12}$ Obstruction of the upper limb of the intraatrial baffle at the venoatrial junction may lead to superior caval venous syndrome. The elevated pressure in the superior caval vein does not always correlate with the symptoms of headache, upper venous distension, chylothorax, and cerebral oedema. Alternative venous pathways are canalized, including the azygos or hemiazygous, inter- 

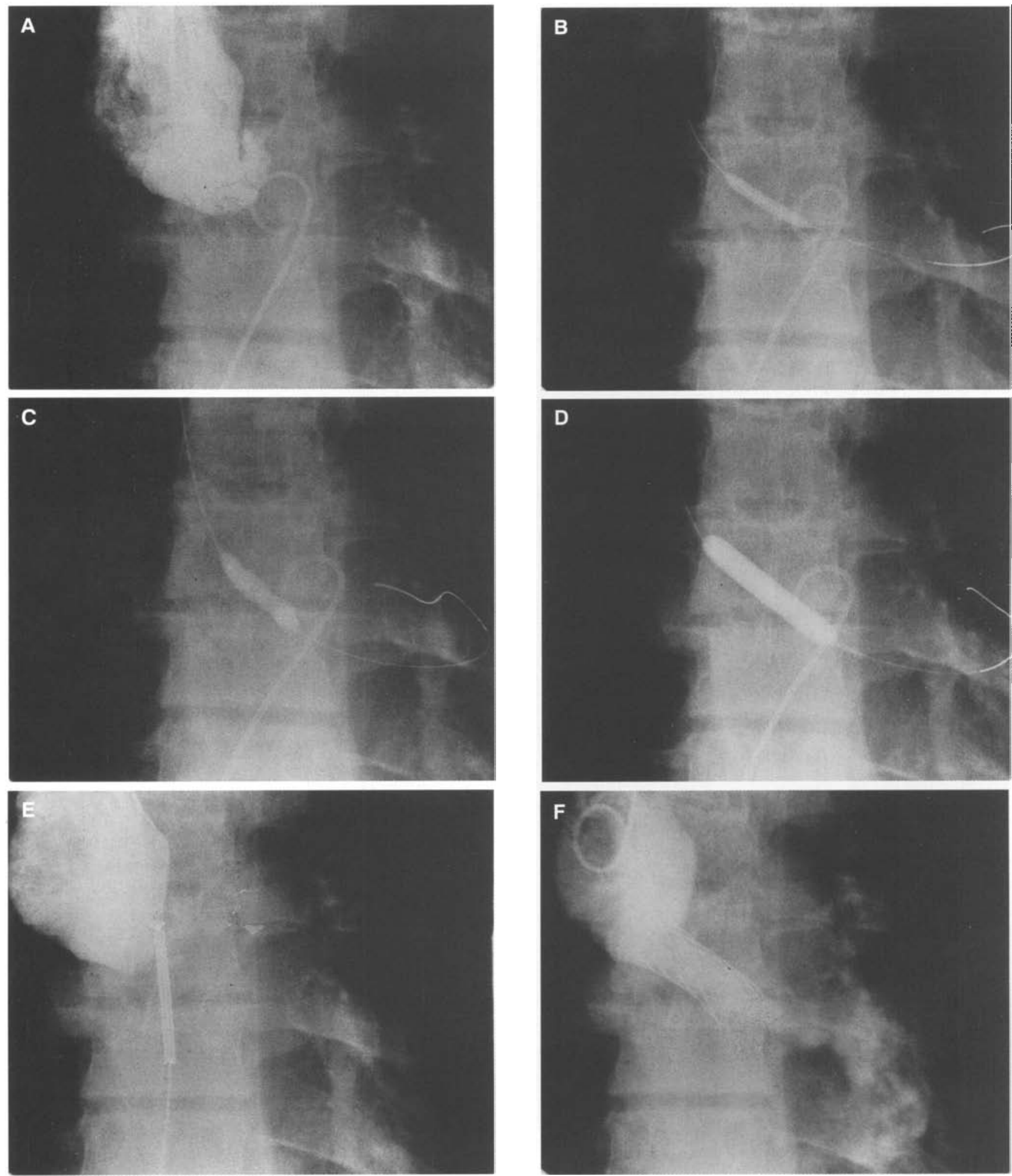

\section{Figure 1.}

Angiograpbic imaging of the stepwise reopening of a completely obstructed venoatrial junction after Mustard repair in patient 4. A). Posterioranterior view of the upper limb of the venoatrial tunnel, with no communication to the systemic venous atrium, showing also the facing position of the catheters in the superior caval vein and the systemic venous atrium. B). Balloon dilation (Olympix $4 \mathrm{~mm} \times 20 \mathrm{~mm}$ ) of the newly created venoatrial communication. C). Gradual dilation with a balloon diameter of $6 \mathrm{~mm} \mathrm{D}$ ). Augmentation of the stenotic area with a balloon diameter of $8 \mathrm{~mm}$. E). Reopened but narrowed venoatrial channel after balloon dilation, with the mounted, noninflated $40 \mathrm{~mm}$ Palmaz-Schatz stent in the venoatrial junction, still covered by a long sheath. F). Enlarged venoatrial junction after placement of a Palmaz-Schatz stent $40 \mathrm{~mm}$ long, $12 \mathrm{~mm}$ O.D.

Abbreviations: $S C V=$ superior caval vein, $R A=$ right atrium 


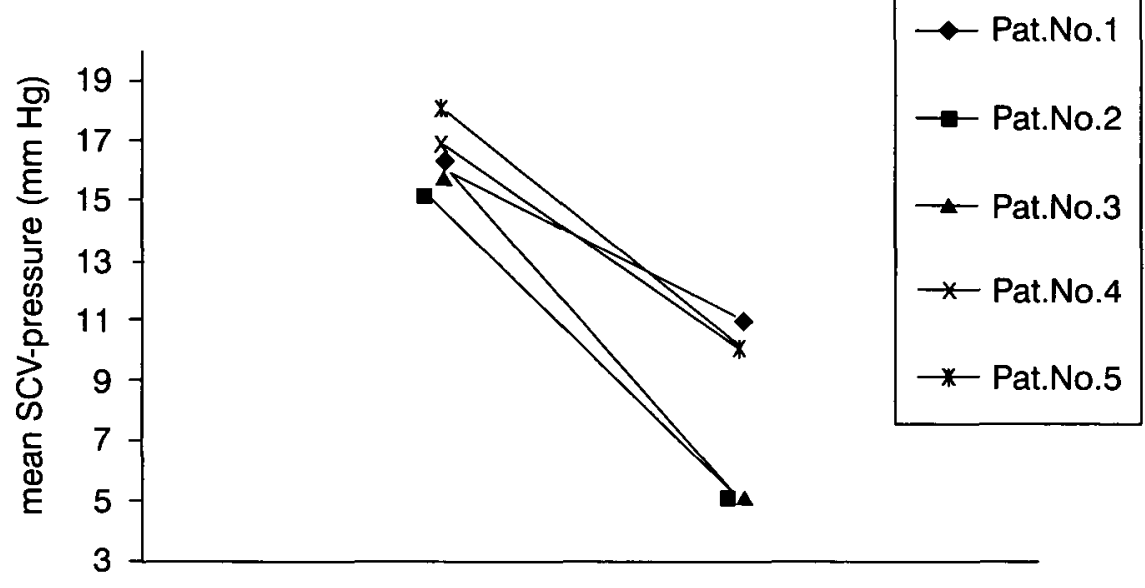

Figure 2.

Drop in pressure in the superior caval vein after recanalisation and placement of a stent in the venoatrial junction in 5 patients with superior caval venous syndrome occurring after Mustard procedure. All measurements are mean values before and after recanalization in the superior caval vein. nal mammary, lateral thoracic and superficial cutaneous veins. ${ }^{1,3}$

Surgical relief is technically difficult and requires general anesthesia. The essential cardiopulmonary bypass carries a high risk for further deterioration of the systemic right ventricle. Furthermore recurrence of systemic or pulmonary venous obstruction, or significant residual stenosis after repeated surgery, may occur in up to one fifth even in experienced hands. ${ }^{4,12}$ Balloon dilation alone provides only transient relief of such tight obstructions. Our study shows that implantation of stents is a safe and effective treatment for these lesions. Despite the fact that perforation of the atretic segment was uncomplicated in our patients, this procedure is not without risk. Inadvertent perforation of adjacent structures, either using the guide wire or transseptal needle technique and dilation with an exaggeratedly large balloon size, may produce uncontrollable haemorrhage. ${ }^{6}$ To minimise these risks, accurate angiographic delineation of the anatomy of the superior limb of the Mustard baffle, and estimation of the length of the obstructed area, is essential. We therefore used a double catheter technique with simultaneous injection if possible. Perforation of the occluded area using a straight guide wire was feasible in all 5 patients. Using the guide wire in this fashion avoids the need to resort to a transseptal needle technique. ${ }^{6}$ Should the obstruction prove to be subtotal, an open ended catheter can be passed without prior dilation. In tight obstructions gradual balloon angioplasty leads to augmentation of the newly created venous channel. Recoil of the surrounding fibrotic material was prevented by placement of Palmaz-Schatz stents of various sizes. Rupture of the balloon during implantation of the stents in two patients confirms that these obstructions were encased in tight fibrous tissue. Stepwise augmentation, with increasingly large balloons prior to placement of stents should help to avoid rupture of the fibrotic tissue at the venoatrial junction. Using a final diameter of the balloon $2 \mathrm{~mm}$ less than the predicted diameter of the fully expanded stent produced an expanded channel at least half the size of the adjacent native segments of the Mustard baffle, and removed any significant residual pressure gradient. We avoided the temptation to expand the stents to their maximum diameter during the first investigation, as it is known that neointimal proliferation may occur when using oversized balloons. ${ }^{6,9}$ In three patients, a final diameter between 14 and $18 \mathrm{~mm}$ (depending on age and morphology of the adjacent structures) after redilation produced an adequate venoatrial channel, even in the two patients in whom two stents were placed in series. Even should there be proliferation of fibrous tissue the chosen diameter of the stent should guarantee adequate flow to the systemic right atrium. Redilation of the stents is optional, especially for the smaller patients either to accommodate an increased volume for venous drainage when they grow up, or to combat neointimal proliferation.

\section{Conclusion}

Complete obstruction at the level of the systemic venous baffle, therefore, can successfully be treated by transcatheter techniques. Interventional recanalisation, followed by gradual angioplasty and subsequent stenting of the obstructed venoatrial junction, is a realistic alternative to high risk surgical procedures. Short- and mid term results suggest excellent hemodynamics, and maintenance of adequate patency. Long term follow up will be required to ensure that there is no restenosis due to neointimal hyperplasia. This interventional approach may will become the treatment of choice for this important problem occurring after the Mustard procedure. 


\section{References}

1. Mahoney L, Turley K, Ebert P, Heymann MA. Long-term results after atrial repair of transposition of the great arteries in early infancy. Circulation 1982; 66:253-259.

2. Helbing WA, Hansen B, Ottenkamp J, Rohmer J, Chin JGJ, Brom AG, Quaegebeur JM. Long-term results of atrial correction for transposition of the great arteries. Comparison of Mustard and Senning operations. J Thorac Cardiovasc Surg 1994;108:363-372.

3. Coulson JD, Pitlick PT, Miller DC, French JW, Marshall WH, Freyer $A D$, Shumway NE. Severe superior vena cava syndrome and hydrocephalus after the Mustard procedure: findings and a new surgical approach. Circulation 1984;70 (suppl I):47-53.

4. Stark J. Reoperations after Mustard and Senning operations In: Stark J, Pacifico A (eds.) Reoperations in cardiac surgery. Springer Verlag, London, 1989, pp 205-224.

5. Chatelain P, Meier B, Friedli B. Stenting of the superior vena cava and inferior vena cava for symptomatic narrowing after repeated atrial surgery for $\mathrm{D}$-transposition of the great vessels. Br Heart J 1991;66:466-468

6. Ward CJB, Mullins CE, Nihill MR, Grifka RG, Vick W. Use of intravascular stents in systemic venous and systemic venous baffle obstructions. Circulation 1995;91:2948-2954.

7. O'Laughlin MP, Slack MC, Grifka RG, Perry SB, Lock JE, Mullins CE. Implantation and intermediate-term follow-up of stents in congenital heart disease. Circulation 1993;88:605614 .

8. Schranz D, Michel-Behnke I, Schmid FX, Oelert H. Gradual angioplasty and stent implantation to treat complete superior vena cava occlusion after Mustard procedure. Cathet Cardiovasc Diagn 1996;38:87-90.

9. Fogelman R, Nykanen D, Smallhorn JF, McCrindle W, Freedom RM, Benson LN. Endovascular stents in the pulmonary circulation. Clinical impact on management and medium-term follow-up. Circulation 1995;92:881-885.

10. Mullins CE, O'Laughlin MP, Vick GWIII, Mayer DC, Myers TJ, Kearney DL, Schatz RA, Palmaz JC. Implantation of balloon expandable intravascular grafts by catheterization in pulmonary arteries and systemic veins. Circulation 1988;77:188-199.

11. Rao PA, Thapar MK. Balloon dilatation of other congenital and acquired stenotic lesions of the cardiovascular system. In:Rao PS (ed). Transcatheter Therapy in Paediatric cardiology Wiley-Liss, New York, 1993,pp 275-319.

12. Cooper SG, Sullivan D, Bull C, Taylor J. Balloon dilatation of pulmonary venous pathway obstruction after Mustard repair for transposition of the great arteries. J Am Coll Cardiol $1989 ; 14: 194-198$ 